phenomena) is derived on simple kinetic grounds, and is shown to agree reasonably well with the available experimental data. The equation, which can only be a first approximation to the truth, is compared with other equations previously proposed. Kinetic treatment also leads to a reasonable equation for the rate of diffusion of water within a zeolite crystal. The condition of the water in the zeolites is discussed.

\title{
CORRESPONDENCE.
}

\section{ATLANTIC SUBSIDENCE.}

Sir,--In the Geological Magazine for February and April Cosmo Johns suggests a temporary lowering of the oceans in Quaternary time of the magnitude of about 3,000 feet.

As only a fraction of this could be used in the formation of Continental ice-sheets, the major action must have been the deepening of the oceanic basins. As the floors can only sink when space becomes available for them, there must have been lateral movement wedging out and elevating the Continental segments. If the suggested re-elevation had taken place in the ocean floors, where there is neither accumulation nor denudation, the submarine contours should show it.

In 1930, by using all the deep soundings in the possession of the Admiralty, I was able to contour the bottom of the Atlantic. This detailed work, while confirming the general outline of the published bathygraphical maps, revealed a number of troughs radiating outwards from the extensive flat oceanic plains into both the mid-Atlantic Rise and the Continental margins. These troughs fork until they die out as single faults. They are recognized on the coasts as bays, estuaries, and fjords.

Except possibly in their upper courses, "drowned" rivers are structural and not erosion features; the stream having taken the easiest path, which is frequently a line of dislocation. As these troughs go right down to the deepest oceanic levels, frequently over 15,000 feet below the surface, they cannot be caused by erosion as there would have been no place available for the sea itself.

This structure of a basin with troughs radiating into the margin is typical of a depressed area. The last movement in the Atlantic basin is shown to be depression and there is no indication of any extensive elevation ever having taken place. This is more eridence in favour of the old theory of permanence of ocean basins.

Major faults that have been active since Carboniferous time illustrate the rule that when a fault develops in a structure the drop continued to be repeated in the same direction until the strain is taken up by a major movement elsewhere. 
There are planets with more than one satellite and the Earth after developing one moon would retain the tendency to produce more. It is not unreasonable to consider the continents as aborted moons. There is no insulation against gravity and sub-crustal rock tides are ready to act when conditions are favourable for the migration of sub-crustal material. The general movement would be to wedge out the continental segments and transfer material laterally into them from the uppermost layers of the plastic zone of the sial of the oceanic floors. The result is a continued deepening of the oceanic basins, a thinning of the sub-oceanic sial, and an increase in the thickness of continental sial. Denudation has little effect as the products are deposited on the continent itself or on its flanks.

The Atlantic submarine contouring gives no support to the theory of continental drift but indicates a drift of sub-crustal oceanic sial into the continental areas.

LesLie H. Ower.

The Rhodesian Museum,

P.O. Box 240,

Bulawa Yo,

SOUTHERN RHODESIA. 8th May, 1934. 